\title{
Bastidores de uma pesquisa: a (in)visibilidade dos prazeres, das sexualidades e dos gêneros na formação em psicologia
}

\author{
Danielle Jardim Barreto ${ }^{1}$ \\ Universidade Paranaense \\ Wiliam Siqueira Peres ${ }^{2}$ \\ Universidade Estadual Paulista
}

Resumo: A proposta deste artigo que agora apresentamos é dar visibilidades à docência engajada politicamente às questões de sexualidades, prazeres e gêneros na formação de psicólogas e psicólogos no Brasil. Utilizamos os seguintes dispositivos metodológicos: as cartografias, as narrativas, as análises dos discursos com ênfase aos conjuntos críticos e genealógicos, e processos de textualização e transcriação das entrevistas a serem trazidas e dos dispositivos que dela anunciaram-se. Esses dois conjuntos de análise agenciaram os rizomas, as problematizações a serem feitas, criando platôs que apontaram várias saídas para: Sobre quais Psicologias problematizamos; como são os territórios em que estão sendo produzidos os nossos corpos, com metas de normalização; como as engrenagens alimentadas e mantidas na razão científica, como as tecnologias, as disciplinas e os múltiplos dispositivos de subjetivação estão tornando assim as pessoas cada dia mais dóceis, úteis e submetidas aos discursos dogmáticos neo cristãos, através de práticas de controle e objetivação, encarcerando as vidas em identidades a serem desejadas pela intervenção/pesquisa dos saberes tradicionais e escassos de um certo tipo de Psicologia.

Palavras-chave: formação em psicologia; narrativas; sexualidades; gêneros, cartografias.

\footnotetext{
${ }^{1}$ Doutora e mestra em Psicologia e Sociedade pela Universidade Estadual Paulista "Júlio de Mesquita Filho" (2002 e 2016), com graduação em Psicologia pela mesma universidade (1998). Membro do grupo de Pesquisa: Psicologias, coletivos e Cultura Queer (PsiCuQueer) na Unesp/Assis (SP).

2 Possui graduação (1985) e mestrado (2005) em Psicologia pela Universidade Estadual Paulista Júlio de Mesquita Filho (1985), doutorado em Saúde Coletiva pela Universidade do Estado do Rio de Janeiro (2005) e pós-doutorado em Psicologia e Estudos de Gênero pela Universidade de Buenos Aires. Professor de graduação e pós-graduação (mestrado e doutorado) em Psicologia da Universidade Estadual Paulista Júlio de Mesquita Filho, campus de Assis/SP. Atualmente é professor aposentado.
} 


\title{
Behind the scenes of a research: the (in)visibility of pleasures, sexualities and genres in qualification in psychology
}

\begin{abstract}
The purpose of this article that we now present is to give visibility to the politically engaged teaching on issues of sexualities, pleasures and genders in the qualification of psychologists in Brazil. We used the following methodological devices: cartographies, narratives, discourse analysis with emphasis on critical and genealogical sets, and processes of textualization and transcreation of the interviews to be presented and the devices that were announced by them. These two sets of analysis managed the rhizomes, the problematizations that will be made, creating plateaus that pointed out several ways for: About which Psychologies we problematize; how are the territories in which our bodies are being produced, with normalization goals. How the gears fed and maintained in scientific reason, how technologies, disciplines and multiple devices of subjectification are thus making people more and more docile, useful and subject to Neo-Christian dogmatic discourses, through practices of control and objectification, incarcerating the lives in identities to be desired by the intervention/research of traditional and scarce knowledge of a certain type of Psychology.
\end{abstract}

Keywords: qualification in psychology; narratives; sexualities; genders; cartography.

\section{Detrás de escena de una encuesta: La (in)visibilidad de los placeres, sexualidades y géneros en la formación en psicología}

\begin{abstract}
Resumen: El propósito de este artículo que ahora presentamos es dar visibilidad a la enseñanza políticamente comprometida en temas de sexualidades, placeres y géneros en la formación de psicólogos y psicólogos en Brasil. Se utilizaron los siguientes dispositivos metodológicos: cartografías, narrativas, análisis del discurso con énfasis en conjuntos críticos y genealógicos, y procesos de textualización y transcreación de las entrevistas a traer y los dispositivos que se anunciaron. Estos dos conjuntos de análisis manejaron los rizomas, las problematizaciones a realizar, creando mesetas que señalaron varias salidas: Sobre qué Psicologías problematizamos; cómo son los territorios en los que se están produciendo nuestros cuerpos, con objetivos de normalización; cómo los engranajes alimentados y mantenidos en la razón científica, cómo las tecnologías, disciplinas y múltiples dispositivos de subjetivación van haciendo así a las personas cada vez más dóciles, útiles y sujetas a los discursos dogmáticos neocristianos, a través de prácticas de control y objetivación, encarcelando las vidas en identidades s deseado por la intervención / investigación de conocimientos tradicionales y escasos de un determinado tipo de Psicología.
\end{abstract}

Palabras clave: formación en psicología; narrativas; sexualidades; géneros; cartografías. 
$\mathrm{O}$ s disparadores para a realização da presente pesquisa, agora organizada num roteiro de artigo, mostravam incômodos que atravessavam a ambos, orientanda e orientador, de modo a problematizar a respeito dos currículos teóricos e práticos que participavam da formação em Psicologia, com suas ênfases e estágios na formação profissional.

Durante as discussões para as mudanças curriculares, entre 2005 e 2018 muitas questões nos afetaram a respeito de discursos de defesa de certa identidade profissional, que obrigatoriamente passava pela clínica tradicional, em suas facetas mais biomédicas, quais sejam: escuta clínica, diagnóstico e protocolos, e cura/acolhimento/acomodação. Havia discursos explícitos de colegas professoras/docentes que formar alunos em outras vertentes teóricas, metodológicas e de campo profissional que atestava certo desconforto, tanto nas universidades que trabalhávamos quanto advindos de outras instituições que dialogávamos. No caso específico de temas transversais como gêneros e sexualidades e outros marcadores interseccionais, em perspectivas que não as da psicanálise era praticamente uma heresia epistemológica.

A cada ano percebíamos discrepâncias na divisão de alunas e alunos por ênfase, com claras manipulações discursivas sobre a não identidade da profissão para aqueles que escolhessem a ênfases diferentes das já validadas na atuação psi em detrimento da ênfase em processos clínicos, marcando hierarquias em disputa.

Como exemplo de mudanças nos campos de problematização de saberes e fazeres psi tinham como opção de escolha de ênfase, os campos de atuação nos estágios específicos e as disciplinas de ênfase em processos psicossociais, que dialogam com áreas de políticas públicas em desenvolvimento social, jurídico e políticas públicas de saúde; os conteúdos iam de Direitos Humanos à Psicologia Institucional de Saúde Mental, além das disciplinas do Núcleo Comum. A ênfase preparava alunas e alunos para atuações em gestão de serviços e em rede psicossocial, além de desenvolver habilidades e competências de problematização da realidade através da análise dos diversos marcadores sociais como classes, etnias/raças/cores, gêneros e sexualidades, sexos e prazeres.

Porém, segundo outros membros do Núcleo Docente esse "novo" currículo estava descaracterizando a formação da profissão, e por alguma razão, a maioria das alunas e alunos também acreditava que só seriam profissionais da Psicologia de fato se escolhessem e se formassem na ênfase de processos clínicos, através de estágios clássicos em atuação psicoterapêutica individual nas mais frequentes correntes teóricas da Psicologia no Brasil, quais sejam: Psicanálise, Análise do Comportamento e as de base Humanistas - Existencial.

As questões que não nos paravam de incomodar eram: Há uma única identidade profissional a ser formada na Psicologia? Por que quando não atuamos com os temas clássicos, como psicoterapias individuais, perdemos a visibilidade nos corredores e nos debates coletivos? Por que temos sempre que justificar o não uso de instrumentos de mensuração para desenvolver nossos planos de trabalho psi? Por que temos que justificar quando em orientação de Trabalhos de Conclusão de Curso, utilizamos autores não hegemônicos da Filosofia, ou da Antropologia para problematizarmos nossos temas? Por que sempre temos que justificar quando defendemos a laicidade da atuação profissional em detrimento de um crescente aumento de discursos dogmáticos cristãos nas nossas salas de 
aula? Por que precisamos provocar quase que diariamente colegas de trabalho para que problematizem em sala seus conteúdos e suas aplicabilidades nas realidades sociais de nosso país?

Essas questões podem se concentrar nas perguntas que nos trazem até aqui: - Para que estamos formando psicólogas e psicólogos afinal? Que Psicologia ensinamos?

\section{Como fazer essa inquietação virar pesquisa?}

Sempre acreditamos e apostamos que a pesquisa tem que ter implicação, experiências, afetações e compromisso com a produção de conhecimento crítico, de modo a ocupar lugares politicamente engajados e de fomentar narrativas conectadas com a transformação social e cultural. É desse lugar que emergiu a proposta da pesquisa anunciada.

A pesquisa narrativa, segundo Clandinin e Connelly (2011), caracteriza-se justamente por esse entrelaçamento entre os modos de viver e os modos de trabalhar, fazendo com que a pesquisa objetivasse justamente buscar pertencimentos, referências e trocas com colegas fora do nosso universo acadêmico para que a sensação de estarmos deslocados possa ser transformada em potência afirmativa de vida.

Situar-nos nestes agenciamentos, que vislumbravam a emancipação e a autonomia na formação psi, diminui o temor de não estar formando profissionais como deveríamos. As vozes de diferentes professoras e professores de graduação em Psicologia autorizam e empoderam as nossas vozes, fazendo-nos multidão, audíveis, e propiciando assim a visibilidade da formação politizada de nossas alunas e alunos.

Esse acontecimento vem ao encontro das problematizações sobre o fazer pesquisa em Psicologia trazida por Azeredo (2013) e Pocahy (2013), que remetem a urgente necessidade da tomada de posição na produção científica em Psicologia, demonstrando assim, que os caminhos por nós traçados, indicam boas perspectivas de inovações na feitura dessa problematização.

Orientados por essas problematizações, o posicionamento na pesquisa em Psicologia configura a desconstrução do lugar da pesquisadora e do pesquisar neutros, e, para além dessa neutralidade dos corpos que pesquisa, há uma necessária implicação no tema, no que e no para que estejam pesquisando em Psicologia. Porém, essas não são nem ingênuas e nem despretensiosas indagações, pois incomodam grande parte da comunidade científica ortodoxa na própria Psicologia e, principalmente, por esse posicionamento agenciar demandas por outras formas de fazer ciência em Psicologia, menos capturadas pela objetividade e reprodução e mais conectadas às realidades sociais, de modo que, para Azeredo (2013): "Essa não é a ciência que queremos construir na psicologia. Queremos uma ciência que através do posicionamento tenha propostas para enfrentar esses problemas. É preciso uma ciência visionária, como diz Haraway, e não uma ciência sem proposta" (AZEREDO, 2013: 100).

O posicionamento incomoda, mobiliza e, por vezes, torna-se insuportável aos olhos e ouvidos da academia - universidade conservadora. Isso é facilmente constatado quando somos desqualificadas e desqualificados publicamente ao apresentarmos nossos temas de pesquisa-implicação, ou quando questionamos a falta de problematização dos marcadores sociais que são constantemente esquecidos nas considerações, análises e problematizações de pesquisas em Psicologia. 
O texto "Saberes Localizados" de Donna Haraway (1995), trata justamente dos efeitos do posicionamento na pesquisa e da ausência nas pesquisas dos marcadores sociais como gêneros, classes, raças/etnias e outras intersecções nas produções dos saberes científicos. Esse olhar, segundo Haraway (1995: 21), pode nos tornar "responsáveis pelo que aprendemos a ver", sendo procedente quando nos pergunta na íntegra: "Com o sangue de quem foram feitos os meus olhos?” (HARAWAY, 1995: 25). A essa questão complementamos: Quais vozes e quais vidas que foram privilegiadas pelas Psicologias em sua constituição enquanto produção de saberes autônomos?

A nossa implicação com as políticas educacionais que compuseram o campo pesquisado viabiliza a experimentação dos corpos no fazer pesquisa. Nossos corpos, nossas escutas, nossas questões, visaram trazer à tona a potência do ensino, da pesquisa e das estratégias de extensão que contemplem a amplitude dos dispositivos compostos pelas linhas de sexos, sexualidades, gêneros e prazeres, trazendo em tela as implicações dessas amplificações à formação de profissionais da Psicologia (POCAHY, 2013).

Destacando essas afinidades, entre o campo de pesquisa, o procedimento, a posição política da pesquisadora e do pesquisador, somados aos territórios de subjetivação, podemos também relacionar o uso das narrativas na abertura deste artigo, enquanto dispositivo que agencia a posição da cartógrafa e do cartógrafo, que se posiciona e se afeta no terreno do experimentar-fazer-viver a pesquisa. Nesta perspectiva, a cartógrafa e o cartógrafo podem ser assim apresentados:

\begin{abstract}
O que ele quer é participar, embarcar na constituição de territórios existenciais, constituição de realidade. Implicitamente, é óbvio que, pelo menos em seus momentos mais felizes, ele não teme o movimento. Deixa seu corpo vibrar todas as frequências possíveis e fica inventando posições a partir das quais essas vibrações encontrem sons, canais de passagem, carona para a existencialização. Ele aceita a vida e se entrega. De corpo e língua. Restaria saber quais são os procedimentos do cartógrafo. Ora, estes tampouco importam, pois ele sabe que deve "inventá-los" em função daquilo que pede o contexto em que se encontra. Por isso ele não segue nenhuma espécie de protocolo normalizado. (ROLNIK, s/d: 2).
\end{abstract}

A cartografia desestabiliza as metodologias positivistas, compondo-se, enquanto outros possíveis, nos modos de se fazer pesquisa em Psicologia, pois um dos seus princípios é que através de seus múltiplos caminhos, entradas e saídas possam dar visibilidade aos rizomas produzidos e aos dispositivos enunciados para as problematizações que anunciam.

Em consonância com um dos pontos citados, qual seja, - a experiência de saber que vem do fazer, justificamos a metodologia cartográfica adotada, tendo em vista que, ao longo do relato dessa pesquisa, mistura-se nossa própria experiência à formação de psicólogas e psicólogos, nossos conhecimentos das diretrizes curriculares desde o documento até a operacionalização destas na construção de Projeto Pedagógico e nas variadas atividades dele demandadas.

Nossas experiências transbordaram em várias páginas do estudo, às vezes em forma de reflexões sobre os universos vividos (universidade privada- interior) e em outras vezes relatos de outras realidades (universidades públicas - capitais), às vezes em forma de narrativas das nossas experiências, das linhas que nos compõem como pessoas, brancas, casadas, classe média, pesquisadora, pesquisador, professora, professor.

Buscamos trazer para a pesquisa as sensações que vivenciamos ao fazê-la e, talvez, criar territórios que implique quem a ler, afetando-a, fazendo dessa vivência uma experiência política, definindo assim nossa posição de cartógrafa e 
cartógrafo.

Dessa posição teórica metodológica, baseia-se também o método narrativo em pesquisa utilizado, que se caracteriza pela participação de pesquisadora/pesquisador e pesquisadas e pesquisados exigindo ampla implicação e negociação política entre os e as participantes da pesquisa. Em contribuição à proposição acima, Clandinin e Connelly (2011: 77) nos dizem:

\begin{abstract}
Na pesquisa narrativa, as pessoas são vistas como a corporificação de histórias vividas. Mesmo quando os pesquisadores narrativos estudam narrativas institucionais, como as histórias da escola, as pessoas são encaradas como vidas compostas que constituem e são constituídas por narrativas sociais e culturais.
\end{abstract}

Desta forma, antes de negociar as entrevistas que foram elencadas na pesquisa, precisamos nos implicar sobre para que estávamos buscando outras histórias para compor a nossas histórias como docentes pesquisadores. Foi preciso que nos implicássemos em nossas experiências demarcando-as como campos a serem levados em consideração na composição da pesquisa, entendendo - a como territórios de subjetivação, de escrita e invenção de si (RAGO, 2013).

Joan Scott (1999) problematiza a questão da experiência e a produção de conhecimento, em especial no campo da história. Para contribuições nas pesquisas e consequentemente produção de saberes em Psicologia, os estudos e problematizações sobre processos de subjetivação e produção de modos singulares de viver não podem afastar os efeitos das experiências das pesquisadoras e dos pesquisadores.

Ao refletirmos sobre as experiências, não deveríamos nos amparar somente em elementos técnicos, dos relatos das vidas e dos fazeres das pesquisadas e pesquisados, como se estes não fossem implicados na nossa própria vida. As experiências não são simples contos, ou recontos de vidas, são efeitos nos processos de subjetivação e singularização, viabilizando outros cenários e outras possibilidades de vida, de práticas e de agenciamentos de outras linguagens na Psicologia e nos fazeres desta.

Neste sentido, concordamos com a afirmação de Claudia Fonseca em seu artigo "Quando cada caso NÃO é um caso: Pesquisa etnográfica e educação", publicado em 1999, ao nos lembrar que nossa implicação em territórios equivalentes aos dos campos em pesquisa, podem agenciar reflexões e produção de conhecimento autênticos, ao invés de cairmos em armadilhas metodológicas que acabam por generalizar como coletivas e universais, experiencias individuais. Ilustrando:

Ao reconhecer que existem outros "territórios", ele enxerga com maior nitidez os con-
tornos e limites históricos de seus próprios valores. Descentrando o foco de pesquisa
dele para o outro, ele realiza le détour par le voyage - e só assim, completando o pro-
cesso com a volta para a casa, alcança a reflexividade almejada. (FONSECA, 1999: 65)

A pesquisa em Psicologia não pode se distanciar dessa implicação da experiência, pois, ao tomarmos determinadas ferramentas dos métodos validados como cientificamente objetivados para dar visibilidades aos discursos, podemos apenas estar sendo assépticos com as experiências que passam em nós, trazendo um distanciamento positivista na produção científica, mesmo porque não acreditamos na neutralidade e muito menos nas totalizações conclusivas da investigação pragmática e positivista.

A Psicologia para estar em processo de problematização de seus paradigmas epistemológicos e abrir-se de fato para a problematização do que estamos fazendo com as vidas ditas abjetas, precisa da experiência para dar a diferença 
status de singularização, para além das identidades já demarcadas historicamente como fixas e acabadas.

Há uma clara hierarquização no ensino superior brasileiro, e em particular na Psicologia, no qual os investimentos na produção científica ficam claramente restritos a uma parcela bastante pequena do vasto número de cursos de Psicologia no Brasil.

Buscamos ações que favoreçam as vidas acadêmicas da subalternidade, o que implica em considerar as vozes, os modos de falas e dispositivos de escuta que facilitam a subalterna e ao subalterno ser levado a sério no que fala e com isso dar passagens para devires outros que afirmem a vida como potência e expansão (SPIVAK, 2010).

Donna Haraway (1995b) nos dá a indicativa da potência da localização dos saberes dessas vozes subjugadas, dessas estratégias adormecidas pelos grandes centros de produção de conhecimento, o que nos leva incluir os saberes psi, que simplesmente desconhecem as pluralidades das Psicologias implicadas nas causas hoje nomeadas, o que se soma ao alerta dessa autora que os saberes são sempre situados e parciais.

\section{Como vislumbramos dar contornos às histórias contadas: sobre dispositivos e as análises emergentes}

A pesquisa que realizamos constituiu-se da análise crítica e genealógica dos discursos sobre as vidas e das estratégias de ensino de gêneros e sexualidades na formação em Psicologia, produzidos por docentes inseridos na graduação em Psicologia. Os disparadores analisados em forma de capítulos foram efeitos rizomáticos das cartografias documentais e das análises dos dispositivos que se agenciaram, das sete entrevistas de docentes/pesquisadoras e pesquisadores.

Interessou-nos os relatos das experiências de suas vidas e a conexão destas com os projetos de pesquisa, ensino ou extensão universitárias relativos aos dispositivos das sexualidades, dos prazeres e dos gêneros. Adotamos neste trabalho as problematizações sobre os discursos, tratados da seguinte forma por Michel Foucault (1988: 96):

\footnotetext{
Os discursos, como os silêncios, nem são submetidos de uma vez por todas ao poder, nem opostos a ele. É preciso admitir um jogo complexo e instável em que o discurso pode ser, ao mesmo tempo, instrumento e efeito de poder, e também obstáculo, escora, ponto de resistência e ponto de partida de uma estratégia oposta. O discurso veicula e produz poder; reforça-o, mas também o mina, expõe, debilita e permite barrálo. Da mesma forma, o silêncio e o segredo dão guarita ao poder, fixam suas interdições; mas, também, afrouxam seus laços e dão margem a tolerâncias mais ou menos obscuras.
}

Esses dois conjuntos de análise agenciaram as cartografias entendidas como modos de acompanhar processos (BARROS e KASTRUP, 2009), somadas às problematizações a serem feitas, criando platôs que apontaram várias saídas para: Sobre quais Psicologias problematizamos; como são os territórios em que estão sendo produzidos os nossos corpos, com metas de normalização; como as engrenagens alimentadas e mantidas na razão científica, como as tecnologias, as disciplinas e os dispositivos de sexualidades e os gêneros estão tornando assim as pessoas cada dia mais dóceis, úteis e submetidas aos discursos dogmáticos neo cristãos, através de práticas de controle e objetivação, encarcerando as vidas em identidades cristalizadas a serem desejadas pela intervenção/pesquisa dos saberes tradicionais de certa Psicologia. 


\title{
Sobre a metodologia na produção de nossas ferramentas
}

Os dispositivos analisados, os que compuseram os mapas dessa pesquisa, delinearam-se ao longo da mesma, pois o referencial metodológico, conforme já discutido, embasa-se no método cartográfico, defendido por Deleuze e Guattari (1995), que funciona como a produção de um mapa em (des) construção.

Compor os mapeamentos como rizoma significa que ele não tem começo nem fim, pois o mesmo se encontra sempre no meio, entre as coisas, as imagens, as narrativas compondo seu interstício. O rizoma tem sempre como sua composição a conjunção "e, e, e", e neste sentido "entre as coisas não designa uma correlação localizável que vai de uma para a outra e reciprocamente, mas uma direção perpendicular, um movimento transversal que as carrega uma e outra, riacho sem início nem fim, que rói suas duas margens e adquire velocidade no meio" (DELEUZE e GUATTARI, 1995: cc).

Virginia Kastrup (2009: 32) nos indica que o método da cartografia

\begin{abstract}
visa acompanhar processos, e não representar um objeto (...) trata-se sempre de investigar um processo de produção (...) a ideia de desenvolver o método cartográfico para utilização em pesquisas de campo no estudo da subjetividade se afasta do objetivo de definir um conjunto de regras abstratas para serem aplicadas. Não se busca estabelecer um caminho linear para atingir um fim. A cartografia é sempre um método ad hoc.
\end{abstract}

Ao ser lançado no território a ser analisado o cartógrafo sabe que poderá haver oscilações perceptivas e sensoriais que são marcadas pela qualidade dos encontros e pelas afetações, podendo ser fragmentadas e até mesmo sem sentido imediato, o que não se caracteriza como problema; ocorrem misturas de fragmentos históricos, pontas do presente, movimentos emergentes, signos diversos que atestam a existência de uma processualidade em curso, podendo inclusive, tornar o problema em questão mais concreto e bem situado. A isto, podemos ver o surgimento de respostas ou de novas perguntas que podem nos remeter a outras experiências, outras sensações que se desdobram em novas configurações.

Ao cartógrafo cabe uma abertura para re-significar e até mesmo subverter princípios e referências tidas até então como "seguras" e "adequadas" na efetivação da pesquisa inicialmente proposta, e, se lançar no desafio de apreender as novidades e provocações advindas do campo de pesquisa e re-direcionar o novo foco da investigação.

Em suas andanças pelo mundo, através de seus olhos e outros órgãos sensoriais a cartógrafa e o cartógrafo vão estabelecendo critérios em suas escolhas a respeito dos componentes que participarão da cartografia, e esses critérios buscam, nos diz Rolnik (1989: 67),

\footnotetext{
descobrir que matérias de expressão, misturadas a quais outras, que composições de linguagens favorecem a passagem das intensidades que percorrem seu corpo no encontro com os corpos que pretendem entender. Aliás, 'entender', para o cartógrafo não tem nada a ver com explicar e muito menos com revelar.
}

Nossas companheiras e companheiros de caminhada nesta pesquisa, assim como nós, "escolheram" trabalhar, pesquisar e experimentar em si as linhas dos dispositivos das sexualidades, sexos, gêneros e prazeres, como modo ampliado da formação em Psicologia. Essa posição, essas experiências de si é política e tem ressonância nos modos como seus corpos transitam e são (des)conhecidos 
no ambiente acadêmico.

Chamaremos nossas entrevistadas e entrevistados de professoras e professores colaboradores, como nossas parceiras e parceiros de jornada investigativa. Tendo em vista o caráter de pesquisa inquietação - perturbação, dos nossos próprios lugares profissionais, qual seja - professoras e professores de graduação em Psicologia, justificamos a adição do lugar implicação de pessoas envolvidas nessa pesquisa.

Ao localizarmo-nos como também sendo desses lugares, inspiramo-nos em Gilles Deleuze e Claire Parnet (2001: 84), quando apresentam o verbete P de professor, que define esses modos de trabalho nas vidas:

É preciso estar totalmente impregnado do assunto e amar o assunto do qual falamos.
Isso não acontece sozinho. É preciso ensaiar, preparar. É preciso ensaiar na própria
cabeça, encontrar o ponto em que... É muito divertido, é preciso encontrar... É como
uma porta que não conseguimos atravessar em qualquer posição.

E complementamos ainda com Deleuze, que nossas professoras e professores corporificam esse conceito, pois são também inspirações, afinal: "O que faz parte do papel do professor é o que eu disse sobre o ensaio anterior é a inspiração. Esse é o papel do professor" (DELEUZE e PARNET, 2001: 87).

A construção do roteiro das entrevistas feitas com docentes se deu de forma coletiva, com sugestões de outras e outros colegas também professores, em busca de atender aos objetivos da pesquisa e dar visibilidade as estratégias que deslocassem e desconstruíssem as já instituídas metodologias e atuações na formação em Psicologia clássica, ou seja, aquela feita através de e com manuais de formação ultrapassados, nem sempre atualizados e muitas vezes advindos do século XIX (PERES, 2014).

O roteiro elaborado continha nove perguntas disparadoras, que agenciaram oito grandes eixos temáticos, sendo eles: Formação profissional das entrevistadas e entrevistados; entrada na graduação em Psicologia; atuação na formação em Psicologia; relação da atuação com o projeto político pedagógico do curso; autores de referência na atuação; pesquisas e extensões em andamento; métodos e antimétodos na graduação; resistências e posicionamentos éticos/estéticos e políticos na graduação.

Caminhamos nessa pesquisa com sete professores colaboradores, que nos concederam suas histórias na e pela Psicologia. A colaboração se deu, tanto narrando sobre suas vivências enquanto corpos formatados também pelas linhas de subjetivação dos discursos da Psicologia, quanto no lugar de (des)formadores de outros corpos psi, através do ensino, da pesquisa e da extensão nas instituições de ensino superior em que atuam ou atuavam.

Foram feitas entrevistas, sendo todas pessoas brancas e cisgêneras - Máximo, Ivan, Vitor, Lorenzo, Dom e Beija-flor, apenas uma mulher - Maria Clementina; seis efetivamente no momento da entrevista a universidades públicas Máximo, Maria Clementina, Ivan, Vitor, Lorenzo, Dom, apenas dois entrevistados estavam em cidades interioranas (Maringá e Londrina PR) - Dom e Beijaflor, estando as outras e outros cinco em capitais (Porto Alegre, Belo Horizonte, Florianópolis e Rio de Janeiro). Foram feitas quatro entrevistas de modo presencial - Máximo, Vitor, Dom e Beija-flor e três via Skype, todas gravadas em modo digitalizado.

As sete entrevistas passaram pelos processos de transcrição, textualização e transcriação. As transcrições visam à passagem da gravação, da linguagem oral para a escrita na íntegra, com todos os vícios de linguagem, erros de concordância verbal, barulhos externos ao contexto, risos, pausas etc. 
Nas transcrições utilizadas no corpo da tese, foram feitas textualizações para que a leitura fosse mais fluída, na textualização há a retirada dos vícios de linguagem, das pausas e das interferências auditivas registradas na transcrição, para viabilizar uma leitura mais dinâmica da fala.

Essas estratégias de trato com as transcrições do material oral são utilizadas nas pesquisas em História Oral, buscando a validação da fidedignidade dos dados, buscando mais uma vez um lugar ao sol do campo dos saberes ditos científicos e reconhecidos. Vejamos a problematização abaixo:

\begin{abstract}
Consagrando o princípio elementar de que existem diferenças entre uma situação (língua falada) e outra (língua escrita), nota-se que o mais importante na transposição de um discurso para o outro é o sentido que, por sua vez, implica intervenção e desvios capazes de sustentar os critérios decisivos. Por outro ângulo, a incorporação do indizível, do gestual, das emoções e do silêncio, convida à interferência que tenha como fundamento a clareza do texto e sua força expressiva. Em história oral, o reconhecimento do texto procedido pela conferência e pela autorização determina se o colaborador se identificou ou não com o resultado. É essa a grande prova da qualidade. do texto final. (MEIHY e BOM MEIHY, 2007: 139)
\end{abstract}

Como estratégia teórico-metodológica, iniciamos nosso estudo já pelo que nos impulsionou a fazer a pesquisa, quais ferramentas utilizaremos - como as cartografias, os dispositivos, as análises críticas e genealógicas dos discursos da produção dos saberes em Psicologias sobre sexos, sexualidades e prazeres, assim como esses dispositivos se articulam nos fazeres de si de nossos colaboradores professores.

Para tanto, foram feitas as textualizações, e destas foram retiradas o que os autores Meihy e Bom Meihy chamam de "tom vital", dessas textualizações produzimos as histórias de vidas transcriadas, com intuito de já tornar nossos colaboradores professores, leitores e participantes ativos dessa pesquisa.

Buscamos em seus discursos, os agenciamentos de dispositivos disparadores, que dessem visibilidade aos conjuntos críticos narrativas que discutiram as problemáticas da produção dos saberes e dos regimes de verdades sobre as Psicologias hegemônicas, os dispositivos dos sexos, das sexualidades e dos prazeres como linhas de captura e de emancipação de vidas abjetas e subjugadas, que por vezes foram anuladas pelas atuações e saberes psi, assim como pela produção das identidades psi e as possibilidades de desconstruções e desnaturalizações desse (re)conhecimento profissional.

As histórias de vidas textualizadas e transcriadas elucidaram as narrativas de cada professora e professor participante desde sua própria graduação em Psicologia até a atuação na formação atravessada pela ética e estética dos modos de politizarem suas próprias existências. Os trechos foram, antes de serem inseridos na tese, enviados para que cada uma das professoras e dos professores entrevistados escolhessem seus nomes fictícios, assim como caso quisessem, interferissem na feitura da história, acrescentando ou suprimindo trechos nas composições das transcriações feitas.

Para manter o sigilo obrigatório demandado pelos trâmites éticos da pesquisa, envolvendo outros seres humanos, os nomes e outros possíveis dados identificatórios como instituição em que estão lotadas, cidades de origem, etc., foram suprimidos ao longo da escrita, porém, esperávamos que ao lerem a produção, se reconhecessem nas narrativas, lendo suas vozes impressas no trabalho, pois nenhuma vida pode ser em vão, e as contribuições desses participantes mereciam ser nomeada em caixa alta, para que todos soubessem a implicação e a diferença que fazem na formação em Psicologia, em tempos políticos tão estranhos quanto os que estamos vivendo no Brasil de 2021. 


\section{Considerações finais}

A aproximação entre o método cartográfico e o cuidado com o material narrado, apresentado pela metodologia das pesquisas em História Oral, enriquece a própria pesquisa em Psicologia, trazendo o tema das lógicas rizomáticas para o campo, amplificando as entradas e saídas da problematização inicial da pesquisa.

A perspectiva do rizoma nos leva a problematizar o plano de imanência, ou seja, os modos pelas quais as forças são distribuídas sobre o território; no nosso caso, cada entrevista se compõe como um território existencial e prático no sentido de efetivar as afetações produzidas no encontro dos corpos de nossas entrevistadas e nossos entrevistados com os dispositivos acadêmicos e seus modos de ensino, pesquisa e extensão universitária, o que não exclui a relação ampliada em outras esferas da vida e suas implicações políticas na construção das relações. A prática docente não diz só em professar aulas, mas de produzir inquietações e reflexões críticas sobre a vida e suas implicações políticas e éticas que respeitem as demandas existenciais e as problematizações fora das capturas essencialistas que aprisionam os corpos e regulam, controlam as populações.

Os planos de imanência se configuram como territórios para a ocupação e composição de conceitos, de efeitos, de discursos, de imagens e de dispositivos. São pertencentes a um Uno-Todo, em velocidades e formações imensuráveis e indefiníveis. São enunciados que se agenciam em acontecimentos, únicos e infinitos em suas outras possibilidades, que solicitam suas localizações e suas parcialidades. De modo foucaultiano de fazer pesquisas, uma pergunta nunca trará uma resposta definitiva e acabada, mas, formulará novas e inúmeras perguntas.

Os encontros agenciados seriam nossos planos, e os dispositivos problematizados os conceitos que os compõem nesse instante, gerando pensamentos, devires, potência e expansão de vida.

Essa pesquisa fez-se com caráter de pesquisa implicação - intuição, vislumbrando sim novas posições políticas, teóricas e conceituais para a produção de conhecimentos - intensões, na formação em Psicologia.

A ênfase hoje no Brasil está na pós-graduação, gerando, inclusive, diferenciações de tratamento entre professoras e professores que cumprem suas atividades básicas de formação na graduação em detrimento dos que estão nas pesquisas críticas de ponta, nas ruas, com investimento de recursos públicos nacionais. A implicação é essencial para a politização da pesquisa e também do fazer em Psicologia.

Todas as narrativas colaboradoras da pesquisa se posicionaram na defesa da sua localização discursiva referente aos seus desejos sexuais, as suas posições políticas de serem homens e mulheres, e faziam a relação dessa experimentação com as estratégias profissionais comprometidas com a defesa das diferenças humanas, e os embates comprados na atuação docente nas narrativas sobre o como se agencia o interesse pelas questões de gêneros e sexualidades como linhas de produção de políticas de viver e trabalhar.

$\mathrm{O}$ transcorrer das atividades de entrevistas, pode ser sentido neste estudo, como um processo de experimentação ímpar, de deslocamentos vividos referentes à própria experiência docente e a de discente, que propiciaram tanto pensamentos e ideias inquietas, quanto olhares e escutas seduzidas e encantadas com tantas experiências e resistências ofertadas por nossas professoras e professores colaboradores, levando-nos a um misturar-se, como define Deleuze (1997). 
Neste sentido, retornar aos territórios da academia, após as incursões pelas experiências relatadas implicou em dar um norte a um estranhamento sentido durante toda a vida profissional e pessoal. Durante as aulas e nos encontros vividos na pós-graduação, experimentamos pertencimentos aos olhares e sentidos que são atribuídos ao que foi vivido e ao que estamos vivendo.

$\mathrm{E}$ foi justamente na constatação de que as binarizações inviabilizavam outros olhares na formação profissional, assim como em nossas diversas relações sociais, que fomos lançados aos campos de experimentações, de estudos e problematizações que nos autoriza a conhecer outras e outros que se incomodam como a gente para que possamos acreditar e insistir na produção de uma Psicologia laica, política e preocupada com a vida em sua potência maior.

Apesar de nossas apostas nessa Psicologia ampliada de defesa da vida como valor maior, ainda nos deparamos com discursos defendidos em sala de aula, nas redes sociais, nas ruas e nos templos cristãos, que ano a ano nos assustam e nos incomodam imensamente, principalmente pelo alto grau de preconceitos e de manutenção das discriminações, e de alto investimento em estratégias de cura e controle de vidas abjetas.

Foi para essa empreitada de viver e fazer viver a partir de princípios de respeito e de fazer viver vidas que se respeitem e se valorizem, que apostamos nesta pesquisa, que objetiva dar visibilidade às estratégias da vida e de atuação de outras professoras e professores que também são pesquisadoras e pesquisadores dentro de posicionamentos engajados na formação de psicólogas e psicólogos para a vida em suas diferenças e modos de existências transcontemporâneos.

Essa estratégia metodológica não teve intenção de criar territórios de identificação, mas sim de mapear, cartografar as experiências de si, de suas atuações, do trânsito das linhas de subjetivação de estar e serem professoras e professores na graduação em Psicologia.

Em um comentário em sala de aula da pós-graduação no ano de 2012, feita sobre o texto Experiência de Joan W. Scott (1999), Wiliam Peres nos esclarece que essa sensação de pertencimento, "não é descobrir-se em uma identidade, mas em um senso de movimento, de trânsito, de fluidez, em processo de desterritorialização" (sic). Essa experimentação de si dá-se num campo complexo de produção de subjetividades.

Finalizamos este trabalho, com problematizações acerca da produção das identidades psi em interfaces com a valoração da produção de multiplicidades de atuação e produção de conhecimento na formação em Psicologia. Estas ampliações se dariam através da desterritorizalização das estratégias de formação psi ditas tradicionais, que acabam por agenciar certo jeito de se apresentar como psicólogas e psicólogos. Em uma analogia, problematizamos que a desestabilização dos territórios tradicionais da formação em Psicologia, agencia o que Deleuze (1997) chama de gagueira.

A gagueira faz minorar a língua instituída, padronizada, dada como hegemônica, tecendo outros modos de se falar e produzir linguagens. Para nós, a gagueira nas Psicologias de pastoreio, através da parresia, da coragem de dizer a verdade seja ela qual for, singulariza os modos de sermos psi, possibilitando que nos desfaçamos de uma identidade profissional única e totalizada, e nos possibilita sermos devires, ou seja, produzir uma psicologia que dialogue com diversos outros saberes, e, assim, reinventarmos a cada encontro, cada discurso, cada imagem que se misturam no contínuo jogo das afetações.

As estratégias nomeadas metodológicas se misturaram ao fazer essa cartografia, pois ao desenharmos o projeto de pesquisa, analisar e se afetar pelas en- 
trevistas, enquanto cartógrafas e cartógrafos, narrando a nossa própria trajetória, e principalmente, a partir das narrativas de nossas professoras e professores colaboradores, aprendemos a compor outros saberes e fazeres na formação em Psicologia, tornando desde já, a pesquisa inacabada, em processo de amplificação as outras formas de atuação, de escrituras, de produção de saberes e prazeres. É o pensamento violentando a escrita, a ponto de deslocar as linhas duras de escrever, do inventar conceitos, de movimentar o já sabido e se permitir experimentar o descaminho do novo, do intempestivo advindo da pesquisa. Como nos diria Rosi Braidotti (2000: 79): "Yo prefiro ficcionalizar mis teorias, teorizar mis ficciones y practicar la filosofia como una forma de criatividade conceptual". Ou seja, que possamos ficcionar as teorias e teorizar as ficções.

A pergunta que fizemos ao final de cada entrevista: - Qual diferença acredita que faz na formação de psicólogas e psicólogos? Nos fazíamos todo dia ao final de uma aula, de uma orientação de estágio, ou durante os anos dos grupos de pesquisa e extensão. Fazia-nos essa pergunta porque nos sentíamos sozinhos, nos sentíamos diferentes, nos sentíamos pouco capacitados para dar conta do que problematizávamos na graduação, nos sentíamos escassos, nos sentíamos pouco psicólogos. Cada declaração feita pelos nossos professores colaboradores, deram materialidade um sentimento que ainda não havíamos tido até aqui pertença. Pertencer significa fazer parte, não estarmos sozinhos na busca por uma formação mais política, mais estética e mais ética com as minorias, significa vida em abundância, e agora podemos afirmar que as nossas vidas transbordam pertencimento a múltiplos, inventivos e alegres modos de ser psicóloga e psicólogo e produzir Psicologias.

Recebido em 23 de janeiro de 2021.

Aprovado em 31 de maio de 2021.

\section{Referências}

AZEREDO, S. M. "Em defesa do posicionamento na pesquisa em Psicologia”. In TEIXEIRA-FILHO, F. et al (organizadores). Queering: problematizações e insurgências na Psicologia contemporânea. Cuiabá: EdUFMT, 2013.

BARROS, L. P. DE; KASTRUP, V. “Cartografar é acompanhar processos”. In: PASSOS, Eduardo; KASTRUP, Virginia; ESCÓCIA, Liliana da (Orgs). Pistas do Método da Cartografia: pesquisa-intervenção e produção de subjetividade. Porto Alegre, Editora Sulina, 2009.

BRAIDOTTI, R. Sujetos nómades. Buenos Aires: Paidós, 2000.

CLANDININ, D. J.; CONNELLY, F.M. Pesquisa narrativa: Experiência e história em pesquisa qualitativa. Uberlândia: EDUFU, 2011. 
DELEUZE, G. Crítica e clínica. São Paulo: Ed. 34, 1997.

DELEUZE, G.; GUATTARI, F. Mil platôs - capitalismo e esquizofrenia. Vol. 1. Rio de Janeiro: Ed. 34, 1995.

DELEUZE, G.; PARNET, C. O abecedário de Gilles de Deleuze. Transcrição para fins didáticos. Editado no Brasil pelo Ministério da Educação, "TV Escola", 2001.

FERREIRA, A. B. de H. Novo dicionário Aurélio da Língua Portuguesa. Rio de Janeiro: Editora Nova Fronteira. 1986.

FONSECA, C. "Quando cada caso NÃO é um caso Pesquisa etnográfica e educação”. Revista Brasileira de Educação, 10 (1): 58-78, 1999.

FOUCAULT, M. História da sexualidade I: A vontade de saber. Rio de Janeiro: Edições Graal, 1988.

HARAWAY, D. Saberes localizados: a questão da ciência e o privilégio da perspectiva parcial. Cadernos Pagu, (5): 7-41, 1995.

MEIHY, J. C. S. B; BOM MEIHY, F. H. História oral: como fazer, como pensar. São Paulo: Contexto, 2007.

PERES, W. S. "Contra a Psicologia do Sacerdócio: a vida que sangra, pulsa, vibra”. In: MINELLA, Luzinete Simões; ASSIS, Gláucia de Oliveira; FUNCK, Susana Bornéo (orgs.). Políticas e Fronteiras. Tubarão: Copiart, 2014.

POCAHY, F. “Pesquisa - aquentação': Derivas de uma epistemologia libertina”. In: TEIXEIRA-FILHO, F. et al (orgs.). Queering: problematizações e insurgências na Psicologia contemporânea. Cuiabá: EdUFMT, 2013.

RAGO, L. M. A aventura de contar-se: feminismo, escrita de si e invenções subjetivas. Campinas: Unicamp, 2013.

ROLNIK, S. Cartografia Sentimental: transformações contemporâneas do desejo. Editora Sulina, Porto Alegre, 1989.

ROLNIK, S. Cartografia ou de como pensar com o corpo vibrátil. Núcleo de estudos da subjetividade. PUC-SP. s/d.

SCOTT, J.W. "Experiência”. In: SILVA, A. L. da; LAGO, M. C. de S.; RAMOS, T. R. O. (orgs.). Falas de Gênero: Teorias, análise, leituras. Florianópolis: Editora Mulheres, 1999.

SPIVAK, G. C. Pode o subalterno falar? Belo Horizonte: Editora da UFMG, 2010. 